\section{Magnetic, Microplate- Format Plasmid Isolation Protocol for High-Yield, Sequencing-Grade DNA}

BioTechniques 29:786-792 (October 2000)

\begin{abstract}
We have developed a rapid, microplateformat plasmid isolation procedure to purify sequencing-grade DNA templates for high-throughput DNA sequencing operations. A modified lysozyme/boiling method is used to produce a plasmid-containing supernatant that is then purified by iron bead capture. After binding, the beads are pelleted in a magnetic field, washed and the DNA eluted in water. The method yields up to 10 $\mu \mathrm{g}$ plasmid DNA from a 1-mL overnight culture in a deep-well microplate. The procedure is suitable for large-scale experiments, amenable to automation and does not require expensive reagents or equipment. The entire protocol can be completed in as little as $2 \mathrm{~h}$, and one technician with a 96-well pipetting station can process up to 48 plates per day. This protocol is ideal for any highthroughput operation in which template quantity, quality and reproducibility are of primary importance.
\end{abstract}

\section{INTRODUCTION}

Since the advent of thermostable DNA polymerases and cycle sequencing, scientists performing DNA sequencing have had three main choices of sequencing templates: single-stranded phage DNA, double-stranded plasmid DNA or PCR products. Phage DNA has historically been considered the ideal sequencing template because it is single stranded and easily purified, but it can be somewhat unstable and is limited by the size of insert that can be cloned. Plasmids have the advantage of having two strands available for sequencing and better stability but are the most difficult and expensive templates to purify. PCR products are readily used sequencing templates but suffer from polymerase bias during amplification, contamination issues and poor sequencing quality unless extensively purified.

Relatively early in the expansion of the Human Genome Project, a fast and cost-effective M13 recombinant phage purification protocol was made publicly available (7). While it is a somewhat crude preparation, it is easy to perform in a microplate format, yields uniform results and is an outstanding sequencing template. This protocol has been used in at least two major genome centers (Genome Sequencing Center, Washington University and Lawrence Livermore National Laboratories) and is considered a standard method for template purification.

As more experience with genomic sequencing was garnered, it became apparent that it would be advantageous to include plasmid clones in the sequencing effort. The major drawbacks to the wholesale use of plasmids for genomic sequencing are cost and scalability. Many commercial kits currently exist to purify sequencing-grade plasmid DNA in a microplate format, but all are more expensive than phage preparation. In the current era when sequencing costs are accounted for on a per-sample basis, many centers have abandoned plasmid templates for cost reasons alone.

We (unpublished results) and others (2) developed silica-based, microplateformat plasmid isolation protocols to affordably sequence plasmid templates in a high-throughput setting. However, with our plans to increase the sequencing capacity more than tenfold, centrifuge capacity (our silica preparation has six independent centrifugation steps), laboratory space and labor costs soon became limiting factors of the rate of template preparation. Our solution was to develop the protocol outlined below. It is faster than the silica isolation method, requires only two centrifugation steps and still costs pennies per isolation. The technique first produces a lysate by a lysozyme/boiling method $(6,8,9)$. After a solid-phase capture step is used, the DNA is washed and recovered by elution in water $(1,5)$. This method produces microgram quantities of high-quality plasmid DNA for fluorescent sequencing reactions.

\section{MATERIALS AND METHODS}

\section{DNA Isolations}

One-milliliter cultures of plasmid- containing $E$. coli (DH5 $\alpha$ ) are grown in Terrific Broth containing 1.6\% glycerol and $50 \mu \mathrm{g} / \mathrm{mL}$ ampicillin in a deep 96well culture plate. Cultures are shaken at $310 \mathrm{rpm}$ overnight, centrifuged to pellet the bacteria and the media decanted. At this point, the plates can be sealed with aluminum foil and stored frozen at $-20^{\circ} \mathrm{C}$ if the isolation is to be performed later. The pellets are then resuspended by adding $25 \mu \mathrm{L}$ water and vortexing on high speed using a VWR multi-tube vortexer (VWR Scientific Products, West Chester, PA, USA) for $3 \mathrm{~min}$.

Complete resuspension of the pellets is crucial to ensure proper lysis. The bacteria are then lysed by the addition of $70 \mu \mathrm{L}$ lysis solution $(10 \mathrm{mM}$ Tris, $\mathrm{pH}$ 8.0, $1 \mathrm{mM}$ EDTA and 5\% Tween ${ }^{\circledR} 20$ in $5 \mathrm{M} \mathrm{NaCl}$ ) containing freshly added $10 \mu \mathrm{g} / \mathrm{mL}$ molecular biology-grade RNase A and $500 \mu \mathrm{g} / \mathrm{mL}$ lysozyme (Sigma, St. Louis, MO, USA) and vortexing lightly for $30 \mathrm{~s}$. After a 15-min incubation at room temperature, the culture plate is sealed and transferred to a $95^{\circ} \mathrm{C}$ water bath for 10 $\min$. The lysates are then diluted with $300 \mu \mathrm{L}$ water, the plate vortexed briefly and incubated on ice for $15 \mathrm{~min}$. Centrifuging the plate at $2000 \times g$ for 30 min clears the lysates. A $100-\mu \mathrm{L}$ aliquot of the lysate is transferred to a fresh 96-well microplate (carefully excluding the soft pellet) with $115 \mu \mathrm{L}$ hybridization buffer [20\% polyethylene glycol-8000 (Sigma) and 2.5 M NaCl] and $15 \mu \mathrm{L}$ carboxylated iron beads (Seradyn Particle Technology, Ramsey, MN, USA) prewashed three times in 10 volumes $10 \mathrm{mM}$ Tris, $\mathrm{pH} \mathrm{8.0,} \mathrm{and} \mathrm{dilut-}$ ed $1: 10$ in $10 \mathrm{mM}$ Tris, $\mathrm{pH} 8.0$.

The microplate is shaken on a plate vortexer for $10 \mathrm{~min}$ on medium. The plate is then placed on a "donut magnet" plate (Atlantic Industrial Models, Marblehead, MA, USA) until the beads have completely accumulated at the bottom of the plate. While still on the magnet plate, the supernatant is aspirated and the beads are washed three times with $200 \mu \mathrm{L} 70 \%$ ethanol. The plate is dried at room temperature overnight or in a $37^{\circ} \mathrm{C}$ incubator until all of the ethanol has evaporated. The beads are resuspended in $100 \mu \mathrm{L}$ molecular biology-grade water, the solution cleared on the magnetic plate and the supernatant transferred to a fresh microplate. 
Table 1. Sequencing Statistics

\begin{tabular}{|lcccc|}
\hline $\begin{array}{l}\text { Project } \\
\text { Name }\end{array}$ & $\begin{array}{c}\text { Number of } \\
\text { Samples }\end{array}$ & $\begin{array}{c}\text { Successful } \\
\text { Samples }\end{array}$ & $\begin{array}{c}\text { Percentage } \\
\text { Successful }\end{array}$ & $\begin{array}{c}\text { Read Length } \\
\text { Phred q>20 }\end{array}$ \\
\hline Cju & 3153 & 2807 & $89.0 \%$ & 428 \\
Cso & 965 & 904 & $93.7 \%$ & 467 \\
Djk & 1793 & 1582 & $88.2 \%$ & 438 \\
Cve & 3305 & 2937 & $88.9 \%$ & 412 \\
Overall & 9216 & 8230 & $89.3 \%$ & 428 \\
Global sequencing statistics. The number of attempted sequences, number of \\
successful reads (defined as having at least 50 bases with a Phred quality score \\
of 20 or more), percentage of successful reads and read length in bases of Phred \\
quality score of 20 or more are shown for four independent sequencing projects \\
(Cju, Cso, Djk and Cve) along with the aggregate statistics. A base with a Phred \\
quality score of 20 corresponds with a correct base-calling confidence of $99 \%$. \\
\hline
\end{tabular}

\section{DNA Sequencing}

Cycle sequencing was performed on plasmid templates using BigDye ${ }^{\mathrm{TM}}$ terminator sequencing reactions kits and model 377 automated fluorescent sequencers (both from PE Biosystems, Foster City, CA, USA). A typical sequencing reaction is composed of 3-5 $\mu \mathrm{L}$ template, $1.5 \mu \mathrm{L}$ BigDye sequencing kit, $1.25 \mu \mathrm{L}$ dilution buffer $(1 \mathrm{mM}$ $\mathrm{MgCl}_{2}, 40 \mathrm{mM}$ Tris, $\mathrm{pH}$ 9.0) and 2.5 pmol sequencing primer in a $10-\mu \mathrm{L}$ reaction volume. The reactions are cycled in an MJ PTC-225 Tetrad ${ }^{\mathrm{TM}}$ Thermocycler (MJ Research, Waltham, MA,
USA) according to the manufacturer's instructions. After the reaction is com plete, the samples are precipitated with three volumes $95 \%$ ethanol and $2 \mu \mathrm{L}$ molecular biology-grade glycogen (200 $\mu \mathrm{g} / \mathrm{mL}$; Roche Molecular Biochemicals, Indianapolis, IN, USA) overnight at $-20^{\circ} \mathrm{C}$. The sequencing plates are then centrifuged at $2000 \times g$ for $30 \mathrm{~min}$ to pellet the reaction products, spun briefly upside down on a towel to remove the ethanol and resuspended in 2 $\mu \mathrm{L}$ formamide resuspension buffer (PE Biosystems). Approximately $1 \mu \mathrm{L}$ of the sample is then loaded onto a 377 automated DNA sequencer with a 48-

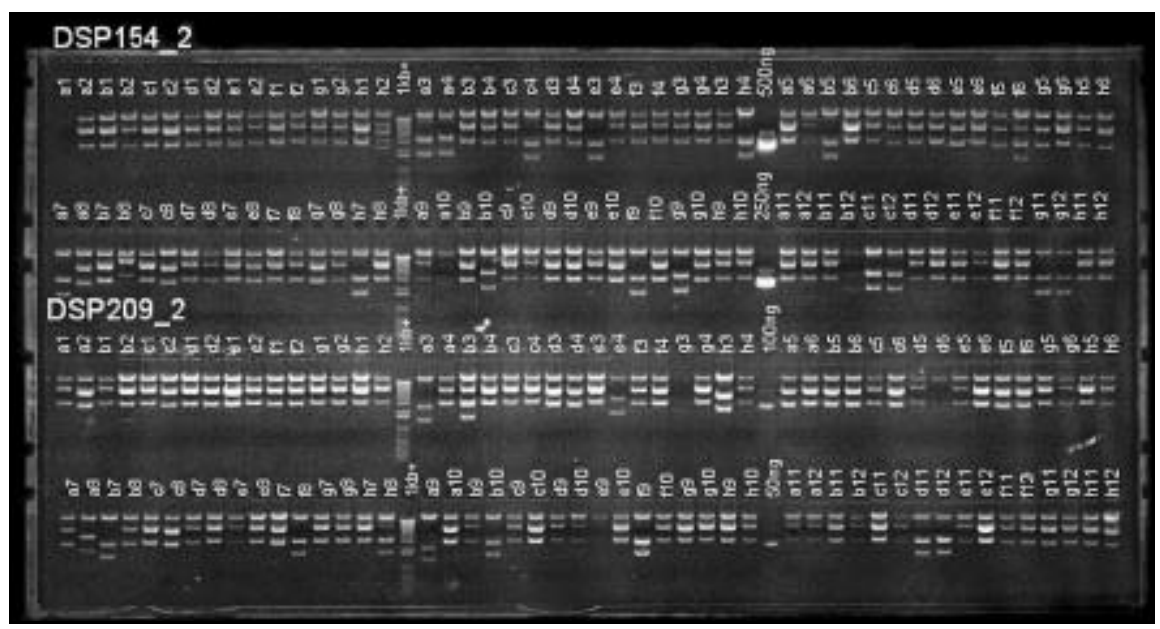

Figure 1. Agarose gel of purified plasmid templates. Each sample, isolated from two plates of isolated plasmid DNA (labeled DSP154_2 and DSP209_2), were run on an 0.8\% agarose/TAE gel containing ethidium bromide at $100 \mathrm{~V}$ for $30 \mathrm{~min}$. Five microliters of each sample were mixed with an equal volume of $2 \times$ gel-loading glycerol solution and loaded with a multiple-channel pipettor along with a 1-kb ladder (1 kb+) and known masses of pBR322 plamid mass standards (500, 250, 100 and $50 \mathrm{ng})$. After electrophoresis, the gel was visualized by UV illumination and photographed. 


\section{Short Technical Reports}

cm, 5.25\% Long Ranger ${ }^{\mathrm{TM}}$ (BMA, Rockland, ME, USA) acrylamide solution gel (64 lanes per well density) and run at $2100 \mathrm{~V}$ for $10 \mathrm{~h}$ on the XL scan mode. The resulting electropherograms are transferred to a UNIX-based server and analyzed with Phred $(3,4)$.

\section{RESULTS}

\section{DNA Isolation}

An agarose gel of two isolations (labeled DSP154_2 and DSP209_2) from 1-mL overnight cultures is displayed in Figure 1. Virtually every lane has at least a detectable amount of DNA, with most displaying between 100 and $250 \mathrm{ng}$. Extrapolating from this amount to the full volume $(100 \mu \mathrm{L}$ total elution versus $5 \mu \mathrm{L}$ loaded onto the gel) gives 2-5 $\mu$ g DNA per isolation on average. The yield of DNA is consistent across the plate, and our experience has shown that most empty wells usually correspond to clones that did not grow and thus had no pellet after the initial centrifugation. While the yield between lanes is often quite variable, quality-control experiments have shown that this is most likely due to variability in plasmid replication, cell growth and inoculation volume (data not shown).

\section{Sequencing}

The Genomics department at Lawrence Livermore National Laboratories uses this method exclusively to generate sequencing templates. Table 1 shows the sequencing success rate and average read length for the four current sequencing projects (named by threeletter library designations). The global sequencing success rate (percentage of reads with at least 50 bases with Phred quality scores of 20 or greater, which corresponds to correct base-calling confidence of $\geq 99 \%$ ) was $89.3 \%$. The average and high-quality read length of successful reads (defined as the number of bases with a Phred quality score of 20 or greater) was 428 bases. These data from more than 90 plates of DNA over a five-month period show that this method yields good sequencing-quality DNA in a consistent manner. A sample electropherogram is shown in Figure 2. The signal is strong, the noise is low and the labeling continues with sufficient strength to allow for good base calls beyond 600 bases where the quality of the read is limited by the resolution of the acrylamide gel.

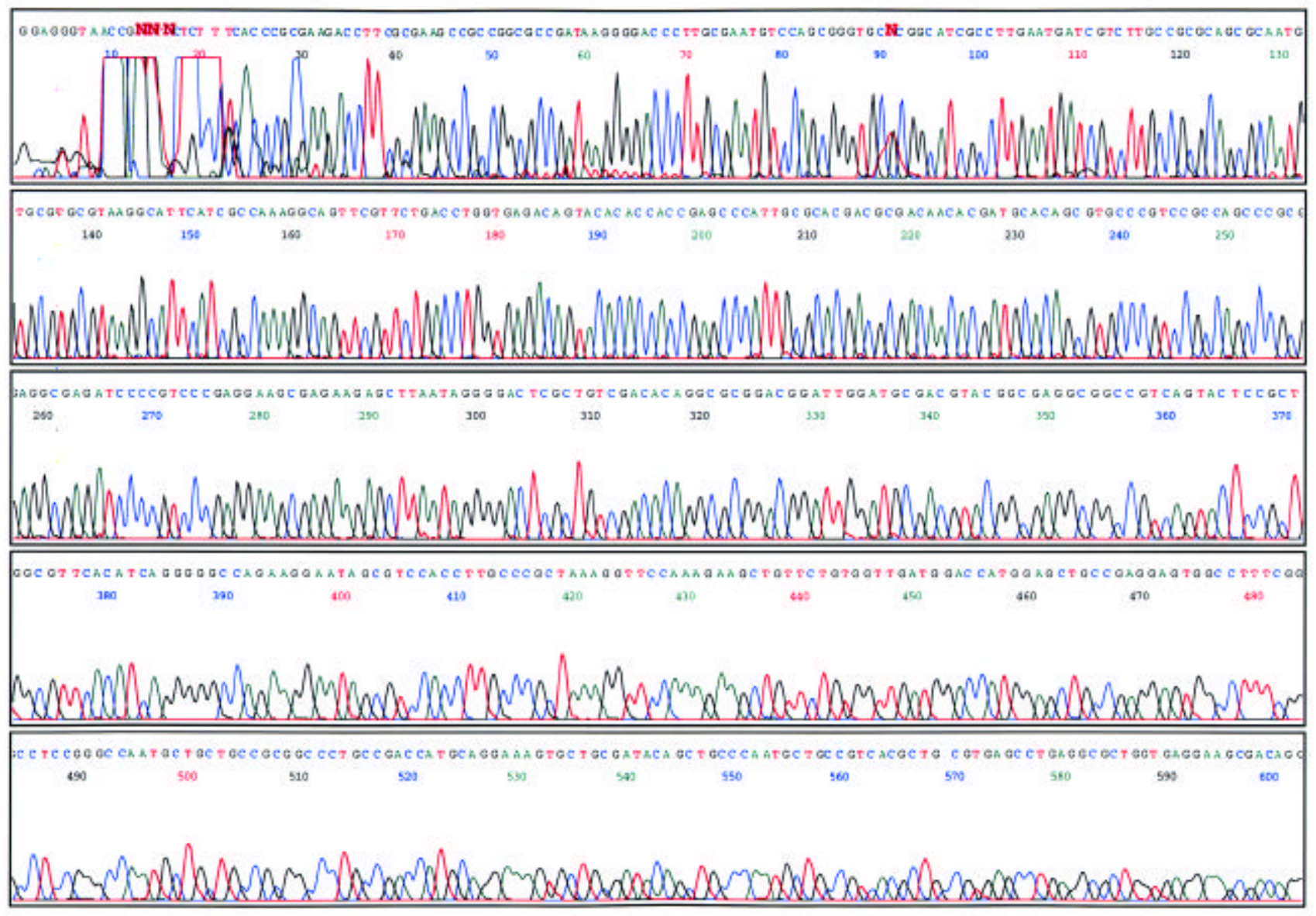

Figure 2. A sample electropherogram from an ABI 377 DNA sequencer. A typical electropherogram showing more than 600 bases of high-quality sequence with good signal strength and low noise. The sequence was obtained with $5 \mu \mathrm{L}$ template in a $0.25 \times$ BigDye terminator reaction followed by ethanol/glycogen precipitation and electrophoresis on an ABI 377 automated DNA sequencer. 


\section{Short Technical Reports}

\section{DISCUSSION}

This protocol was developed primarily from two preexisting microplate-format protocols [boiling lysozyme/detergent lysis (8) and magnetic particle DNA capture $(1,5)]$ in an effort to streamline our plasmid template isolation efforts while ensuring low costs and high-quality templates. Traditional alkaline lysis can also be used to produce the lysate, but the yield is consistently two- to threefold higher using the high-salt lysozyme/boiling method (data not shown). The yield is excellent for the small culture volume, and the DNA is clean enough to give remarkable sequence quality in both capillary and slab-gel electrophoresis units. More importantly, the method has few centrifugation steps (and no vacuum manifold requirements) compared with other protocols, which dramatically shortens the processing time and makes it amenable to automation. The cost remains at pennies per well, which is only a fraction of the least expensive commercial kit on the market. The DNA produced by this method is also useful for a variety of other molecular biology applications (e.g., PCR, restriction mapping, subcloning), but inconsistent UV spectrophotometric 260 $\mathrm{nm} / 280 \mathrm{~nm}$ ratios (data not shown) indicate that there are contaminants that might render it unsuitable for applications requiring higher-purity DNA.

Perhaps the most important aspect of this application is its adaptability to various "off-the-shelf" instruments for assistance in sample handling. It has been shown in two laboratories at Lawrence Livermore National Laboratory using this protocol that multiple-channel pipettors, Hydra ${ }^{\circledR}$ 96-well pipetting stations (Robbins Scientific, Sunnyvale, CA, USA) and custom robotic workstations can be successfully used to imple- ment this protocol. The only unique piece of equipment that needs to be purchased in bulk is the magnetic plates. These plates are small, inexpensive and have a long usable lifetime. Most laboratories that isolate plasmid DNA in any quantity usually have the instrumentation to perform this protocol with only minimal up-front expenditures for magnetic plates and carboxylated beads.

\section{REFERENCES}

1.DeAngelis, M.M., D.G. Wang and T.L. Hawkins. 1995. Solid-phase reversible immobilization for the isolation of PCR products. Nucleic Acids Res. 23:4742-4743.

2.Engelstein, M., T.J. Aldredge, D. Madan, J.H. Smith, J.I. Mao, D.R. Smith and P.W. Rice. 1998. An efficient, automatable tem plate preparation for high throughput sequencing. Microb. Cop. Genomics 3:237-241

3.Ewing, B. and P. Green. 1998. Basecalling of automated seqeuncer traces using PHRED II. Error probabilities. Genome Res. 8:186-194. 


\section{Short Technical Reports}

4.Ewing, B., L. Hillier, M. Wendle and P. Green. 1998. Basecalling of automated sequence traces using PHRED I. Genome Res. 8:175-185.

5.Hawkins, T.L., T. O'Connor-Morin, A. Roy and C. Santillan. 1994. DNA purification and isolation using a solid phase. Nucleic Acids Res. 22:4543-4544.

6.Hultner, M.L. and J.E. Cleaver. 1994. A bacterial plasmid DNA miniprep using microwave lysis. BioTechniques 16:990-994.

7.Mardis, E.R. 1994. High-throughput detergent extraction of M13 subclones for fluorescent DNA sequencing. Nucleic Acids Res. 22:2173-2175.

8.Marra, M.A., T.A. Kucaba, L.W. Hillier and R.H. Waterson. 1999. High-throughput plasmid DNA purification for three cents per sample. Nucleic Acids Res. 27:e27.

9.Sambrook, J., E.F. Fritsch and T. Maniatis 1989. Molecular Cloning: A laboratory manual, 2nd ed. Cold Spring Harbor Press, Cold Spring Harbor, NY.

This work was performed under the auspices of the U.S. Department of Energy by Lawrence Livermore National Laboratory under contract No. W-7405-Eng-48. The authors would like to thank Elaine Mardis from the Washington University Genome Sequencing Center for discussions and methods for lysozyme/boiling plasmid preparations in microplate format. We would also like to thank Genevieve Johnson and Tina Attix from Lawrence Livermore National Laboratories for their insight into the use of this preparation in a highthroughput setting and assistance gathering data for this manuscript. Finally, we thank Pat Fitch at Lawrence Livermore National Laboratories for his insight, suggestions and support while preparing this manuscript. Address correspondence to Dr. Evan W. Skowronski, MJ Bioworks, Inc., 384 Oyster Point Blvd., Ste. \#8, South San Francisco, CA 94080,USA. e-mail: evans@ bioworks. com

Received 23 November 1999; accepted 1 June 2000.

E.W. Skowronski, $\mathbf{N}$. Armstrong, G. Andersen, M. Macht and P.M. McCready

Lawrence Livermore

National Laboratories

Livermore, CA, USA

\section{Method for Linking a Synthesized Protein to Its mRNA-DNA Complex}

BioTechniques 29:792-798 (October 2000)

\section{ABSTRACT}

A nascent protein remains in a complex with its ribosome and $m R N A$ if the stop codon is deleted from the mRNA. In the same manner, mRNA forms a stable com plex with DNA if the transcription termination is blocked. In principle, if both $m R N A$ translation and DNA transcription termination are prevented, the protein should stay in a complex with its $m R N A$ and DNA. A method is designed to test these possibilities. Using an immobilized luciferase gene sequence, a functional luciferase protein is produced that remains associated through its $m R N A$ with its DNA, confirming the feasibility of the proposed scheme. It has potential application for in vitro synthesis of proteins and protein micro-arrays.

\section{INTRODUCTION}

Protein production is the result of the two-step process of transcription and translation. During translation, the protein is in a stable complex with mRNA via the ribosome. At the end of translation when the ribosome reaches a stop codon, the newly synthesized protein is released from both the ribosome and the mRNA. Similarly, in transcription, the mRNA stays associated with the DNA through RNA polymerase and is released when the polymerase reaches a termination signal. To link the newly synthesized protein to its DNA, we prevent the termination of transcription and translation.

Translation termination is prevented by deleting the sequences that encode the stop codon from the initial DNA. Without a stop codon, the ribosome will move along the mRNA to the last codon but will not release the protein $(1,2,6)$. Such coding has been used in experiments to obtain a stable attachment of the protein to the mRNA via the ribosome $(3,4)$. As a further extension of the method, the protein can be covalently linked to its mRNA to achieve a cleaner (i.e., free of ribosome) and more stable protein-mRNA linkage $(8,9)$.

We have developed a method to prevent transcription termination. It consists of binding avidin to one end of DNA that is biotinylated downstream of the coding sequence. This method is analogous to some existing DNA-RNA linking methods such as covalently cross-linking the DNA duplex structure $(12,13)$ or DNA adducts $(7,10,11)$.

If both transcription and translation termination are prevented, the resulting structure is expected to be composed of the protein bound to mRNA through the ribosome, and the mRNA linked to DNA.

In our test, avidin (NeutrAvidin ${ }^{\mathrm{TM}}$; Pierce Chemical, Rockford, IL, USA) is coated on polystyrene beads, and biotinylated DNA is then immobilized on the beads. The test DNA has the luciferase gene $(l u c)$. We verified that the protein stays bound to the DNA through its mRNA by observing that luciferase luminescence is associated with the beads.

\section{MATERIALS AND METHODS}

We used the following buffer solutions. TE: $10 \mathrm{mM}$ Tris, $\mathrm{pH} 8.5,1 \mathrm{mM}$ EDTA; TlowE: $10 \mathrm{mM}$ Tris, $\mathrm{pH}$ 8.5, 0.1 mM EDTA; and TBSM: $10 \mathrm{mM}$ Tris, $\mathrm{pH} 8.0,50 \mathrm{mM} \mathrm{NaCl}$ and $5 \mathrm{mM} \mathrm{MgCl}_{2}$.

\section{DNA Biotinylation and Immobilization on Beads}

Biotin is attached to the $5^{\prime}$-end of a desired DNA primer using a biotinylation kit (Amersham Pharmacia Biotech, Piscataway, NJ, USA) and purified over a G-25 gel filtration column (AmiKa, Columbia, MD, USA). Using one biotinylated primer, the PCR product is biotinylated at the C-terminus of the coding region. NeutrAvidin-coated polystyrene beads of 1- $\mu \mathrm{m}$ diameter (Molecular Probes, Eugene, OR, USA) comprise the solid medium for DNA immobilization. The beads are washed once in TBSM. The DNA and beads are mixed at $1 \mathrm{pmol} \mathrm{DNA} / 10 \mu \mathrm{g}$ beads. The binding reaction is carried out at $37^{\circ} \mathrm{C}$ for $30 \mathrm{~min}$. The coupling efficiency is approximately 50\%. Before 